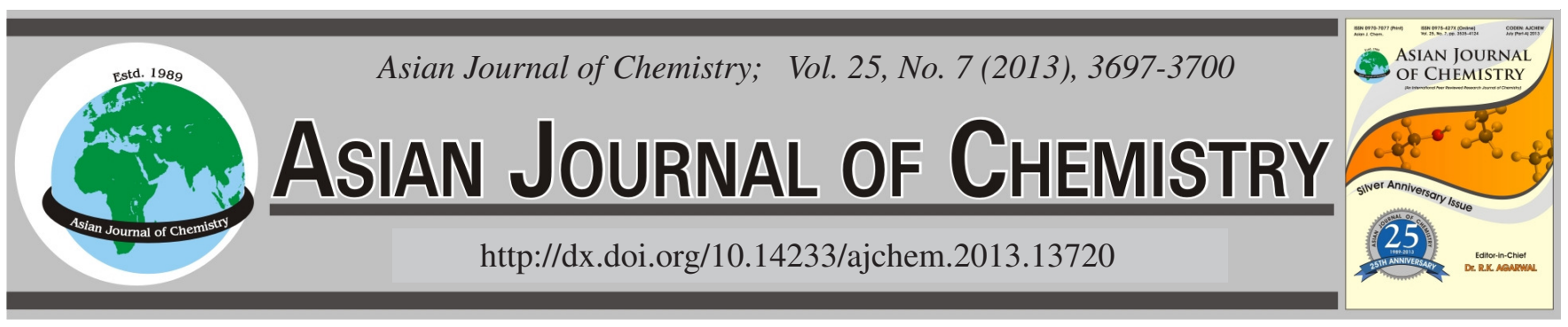

\title{
RP-HPLC Method for Simultaneous Determination of Valsartan and Fenofibrate from PPI Dendrimer
}

\author{
P. Sureshimumar ${ }^{1, *}$, J. ViJAYA RATNA $^{2}$ and N. HematheERThANi ${ }^{3}$
}

\begin{abstract}
${ }^{1}$ Nova College of Pharmaceutical Education and Research, Jupudi, Ibrahimpatnam-521 456, India
${ }^{2}$ Department of Pharmaceutical Sciences, College of Science and Technology, Andhra University, Visakhapatnam-530 003, India

${ }^{3}$ Gurram Balnarasiah Institute of Pharmacy, Ghatkear Mandal, RR District-501 301, India

*Corresponding author: E-mail: pskumar1974@gmail.com
\end{abstract}

The present study aimed at synthesizing PPI dendrimer and loading dual drug followed by developing stability indicating reversed-phase HPLC method and subsequent validation for simultaneous estimation of valsartan and fenofibrate. The proposed RP-HPLC method utilizes a Nucleosil 100, $5 \mu \mathrm{m}, \mathrm{C}_{8}, 250 \times 4.0 \mathrm{~mm}$ column, mobile phase consisting of methanol : $1 \%$ orthophosphoric acid : acetonitrile (45:30:25) and UV detection at $247 \mathrm{~nm}$. The described method was linear over a range of 10-50 $\mu \mathrm{g} / \mathrm{mL}$ for valsartan and 3-15 $\mu \mathrm{g} / \mathrm{mL}$ for fenofibrate. The mean recoveries were 99.91 and $100.53 \%$ for valsartan and fenofibrate, respectively. Statistical data's were used to check the intermediate precision data obtained under different experimental setups. The calculated value was found to be less than critical value.

Key Words: Valsartan, Fenofibrate, Dendrimer, Simultaneous.

\section{INTRODUCTION}

Dendrimer represents a novel type of polymeric material. It is also known as starburst ${ }^{1}$ or cascade ${ }^{2}$ or molecular trees ${ }^{3}$ or arborols, or polymers. They attract the increasing attention of pharmaceutical researchers because of their unique structure, high degree of control over molecular weight and the shape that has led to the synthesis of unimolecular micelles ${ }^{4,5} .5 \mathrm{G}$ EDA-PPI dendrimers were synthesized by reported method ${ }^{6,7}$.

The chemical formula of valsartan is N-(1-oxopentyl)$\mathrm{N}$-[[2-(1H-tetrazol-5-yl) [1,1-biphenyl]-4-yl]methyl]-l-valine (Fig. 1). Valsartan is a potent, highly selective, and orally active antagonist at the angiotensin II AT1-receptor that is used for the treatment of hypertension. Few methods appeared in the literature for the determination of valsartan individually based on high-performance liquid chromatography ${ }^{8-10}$. Sampath et al. ${ }^{11}$ described identification and characterization of potential impurities of valsartan AT1 receptor antagonist. There has been some of estimation of assays of analyte in human plasma including the use of liquid chromatography ${ }^{12-15}$, a gas chromatographic, mass spectroscopic ${ }^{16}$ and some combination with other drugs using high pressure liquid chromatography and derivative spectroscopy ${ }^{17-22}$.

Fenofibrate (Fig. 2), isopropyl 2-[4-(4-chlorobenzoyl) phenoxy]-2-methylpropionate, is fibric acid derivative, used for regulating plasma lipids and treatment of hyperlipopro- teinaemias ${ }^{23}$. The literature survey reveals that fenofibrate was analyzed in environmental water samples using solid phase extraction followed by GC-MS ${ }^{24,25}$ or HPLC electrospray ionization MS-MS ${ }^{24}$. HPLC was used for determination of fenofibrate ${ }^{26-28}$, its metabolites ${ }^{29-33}$ and related impurities ${ }^{34,35}$. Other HPLC methods for assay and purity of fenofibrate and an NMR method for related compounds in fenofibrate raw materials were reported ${ }^{36}$. There are no simultaneous method for the determination of valsartan and fenofibrate. This study aimed to develop a simultaneous method for the estimation of both the drugs by RP-HPLC method.<smiles>CCCCC(=O)N(Cc1ccc(-c2ccccc2-c2nnn[nH]2)cc1)C(C(=O)O)C(C)C</smiles>

Fig. 1. Structure of valsartan 


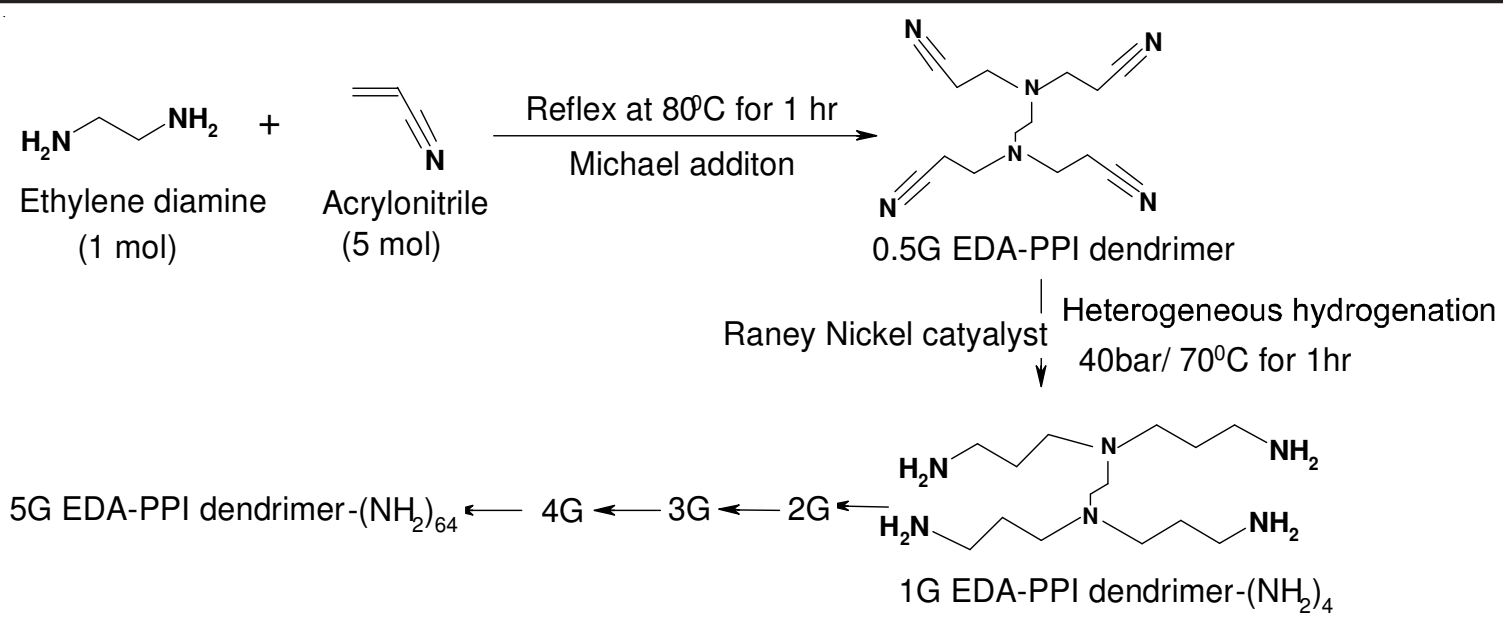

Scheme-I

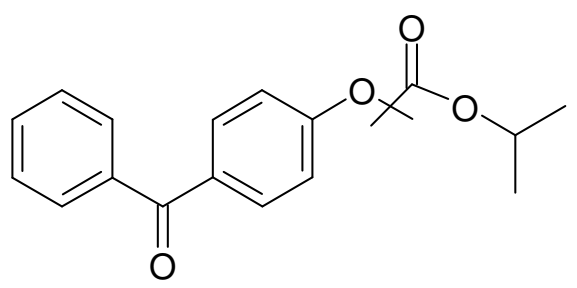

Fig. 2. Structure of fenofibrate

\section{EXPERIMENTAL}

Shimadzu LC-2010 HT with liquid chromatograph, Metller Toledo electronic analytical balance, transsonic digital $\mathrm{S}$ (Sonicator), Chromatographic software-CLASS-VP and Nucleosil 100, $5 \mu \mathrm{m}, \mathrm{C}_{8}, 250 \times 4.0 \mathrm{~mm}$ column was used as a stationary phase, Perkin-Elmer IR spectroscope and Bruker DRX, USA.

Valsartan and fenofibrate were supplied by Microlabs limited, Bangalore. Ethylenediamine, acrylonitrile, Raney nickel, HPLC grades methanol, AR grade ortho phosphoric acid, hydrochloric acid, sodium hydroxide, hydrogen peroxide were procured from E. Merck.

Synthesis of 5G EDA-PPI dendrimers: 5G EDA-PPI dendrimers were synthesized by reported method ${ }^{23,24}$. In brief, ethylenediamine was used as initiator core and acrylonitrile was added to it in a double Michael addition reaction method to produce half generation (-CN terminated), followed by heterogeneous hydrogenation using Raney nickel as catalyst to produce full generation $\left(-\mathrm{NH}_{2}\right)$ dendrimers. The reaction sequence was repeated cyclically to produce PPI dendrimers up to fifth generation (PPI-5G) as shown in Fig. 1 (Scheme-I). Sysnthesiszed dendrimers were characterized by IR (PerkinElmer IR spectroscope) and NMR spectroscopy (Bruker DRX, USA).

Drug loading in formulations: The known molar concentrations of EDA-PPI dendrimer- $\left(\mathrm{NH}_{2}\right) 64$ and valsartan conjugated 5.0G EDA-PPI dendrimers were dissolved separately in methanol and mixed with methanolic solution of fenofibrate (100 mol). The mixed solutions were incubated with slow magnetic stirring (50 rpm) using Teflon beads for $24 \mathrm{~h}$. These solutions were twice dialyzed in cellulose dialysis bag (MWCO 1000 Da Sigma, Germany) against double distilled water under sink conditions for $10 \mathrm{~min}$ to remove free drug from the formulations, which was then estimated spectrophotometrically $\left(\lambda_{\max }\right.$ $475 \mathrm{~nm}$ ) to determine indirectly the amount of drug loaded within the system. The dialyzed formulations were lyophilized and used for further characterization.

Preparation of standard stock solution: About $20 \mathrm{mg}$ of standard Valsartan and fenofibrate were weighed accurately and transferred to a separate $100 \mathrm{~mL}$ volumetric flask with mobile phase and sonicated for 10 min and made up to graduation with mobile phase. The final concentration was prepared by diluting suitable aliquates.

Selection and preparation of mobile phase: Pure drug of valsartan and fenofibrate were injected into the HPLC system and run in different solvent systems. It was found that methanol: $1 \%$ ortho phosphoric acid: acetonitrile gives satisfactory results as compared to other mobile phases. Finally, the optimal composition of the mobile phase employed was 45:30:25 and UV detection at $247 \mathrm{~nm}$. The prepared mobile phase was ultrasonicated for 20 mins.

Selection of analytical wavelength: By appropriate dilution of standard stock solution with mobile phase, various concentrations of Valsartan and fenofibrate were prepared separately. The solutions were scanned using the double beam UV visible spectrophotometer in the spectrum mode between the wavelength ranges of $400 \mathrm{~nm}$ to $200 \mathrm{~nm}$ and $247 \mathrm{~nm}$ which was selected as the analytical wavelength for further analysis.

\section{RESULTS AND DISCUSSION}

System suitability: System suitability parameters were calculated at the start of study of each validation parameter. The values of system suitability results obtained during the entire study are recorded in Table- 1 .

Linearity: Linearity was determined at five levels over the range of $10-50 \mu \mathrm{g} / \mathrm{mL}$ for Valsartan and 3-15 $\mu \mathrm{g} / \mathrm{mL}$ for fenofibrate of test concentration. Each linearity solution was injected in triplicate. The mean area at each level is calculated and a graph of mean area versus concentration is plotted. The correlation co-efficient (r), Y-intercept, slope of regression line, residual sum of squares are calculated and recorded in Table1. The plot of peak area response against concentration is 
TABLE-1

VALIDATION DATA FOR VAL AND FB

\begin{tabular}{|c|c|c|c|c|}
\hline \multicolumn{5}{|c|}{ a) Regression characteristics of the proposed HPLC method } \\
\hline Linearity experiment $(\mathrm{n}=5)$ & \multicolumn{2}{|c|}{ VAL } & \multicolumn{2}{|c|}{ FB } \\
\hline Range $(\mu \mathrm{g} / \mathrm{mL})$ & \multicolumn{2}{|c|}{$10-50$} & \multicolumn{2}{|c|}{$3-15$} \\
\hline Mean 'r' value & \multicolumn{2}{|c|}{0.999} & \multicolumn{2}{|c|}{0.999} \\
\hline Slope & \multicolumn{2}{|c|}{4394.9} & \multicolumn{2}{|c|}{33755} \\
\hline Intercept & \multicolumn{2}{|c|}{671.43} & \multicolumn{2}{|c|}{3739.3} \\
\hline \multicolumn{5}{|c|}{ b) Results of accuracy using proposed method } \\
\hline \multirow{2}{*}{ Accuracy $(n=3)$} & \multicolumn{2}{|c|}{ VAL } & \multicolumn{2}{|c|}{ FB } \\
\hline & \multicolumn{2}{|c|}{$\%$ recovery } & \multicolumn{2}{|c|}{$\%$ recovery } \\
\hline Level 1 & \multicolumn{2}{|c|}{98.87} & \multicolumn{2}{|c|}{101.09} \\
\hline Level 2 & \multicolumn{2}{|c|}{98.24} & \multicolumn{2}{|c|}{98.68} \\
\hline Level 3 & \multicolumn{2}{|c|}{98.92} & \multicolumn{2}{|c|}{101.44} \\
\hline Mean $\%$ recovery $(\mathrm{n}=9)$ & \multicolumn{2}{|c|}{98.68} & \multicolumn{2}{|c|}{100.40} \\
\hline \% R.S.D & \multicolumn{2}{|c|}{0.3841} & \multicolumn{2}{|c|}{1.4966} \\
\hline \multicolumn{5}{|c|}{ c) Results of precision and intermediate precision for VAL and FB } \\
\hline & \multicolumn{2}{|c|}{ VAL } & \multicolumn{2}{|c|}{ FB } \\
\hline & \multicolumn{2}{|c|}{$\begin{array}{c}\text { Mean assay (\%) } \\
/(\%) \mathrm{RSD}\end{array}$} & \multicolumn{2}{|c|}{$\begin{array}{c}\text { Mean assay (\%)/ } \\
(\%) \text { RSD }\end{array}$} \\
\hline Precision $(\mathrm{n}=6)$ & \multicolumn{2}{|c|}{$100.25 / 0.8762$} & 99.65 & 1.2634 \\
\hline Intermediate precision $(\mathrm{n}=6)$ & 100.8 & 0.7856 & 99.88 & 1.1452 \\
\hline d) Results of solution stabilit & for VAL & nd FB & & \\
\hline & VAL $(\%$ & covery) & $\mathrm{FB}(\% \mathrm{r}$ & covery) \\
\hline & $\begin{array}{l}\text { Room } \\
\text { temp. }\end{array}$ & $4{ }^{\circ} \mathrm{C}$ & $\begin{array}{l}\text { Room } \\
\text { temp. }\end{array}$ & $4{ }^{\circ} \mathrm{C}$ \\
\hline Initial & 100.11 & 100.25 & 99.97 & 99.87 \\
\hline After $4 \mathrm{~h}$ & 99.95 & 99.87 & 99.91 & 99.12 \\
\hline After $8 \mathrm{~h}$ & 98.98 & 99.98 & 99.12 & 99.25 \\
\hline After $12 \mathrm{~h}$ & 98.89 & 98.92 & 98.56 & 98.76 \\
\hline After $24 \mathrm{~h}$ & 99.85 & 99.67 & 98.17 & 98.12 \\
\hline
\end{tabular}

presented in Figs. 4 and 5. The Beer Lambert's law was obeyed in the concentration range $10-50 \mu \mathrm{g} / \mathrm{mL}$ for Valsartan and 3$15 \mu \mathrm{g} / \mathrm{mL}$ for fenofibrate. The linearity of calibration graphs and adherence of the system to Beer's law was validated by high value of correlation coefficient.

Specificity: The specificity of the HPLC method was determined by complete separation of both valsartan and fenofibrate in the presence of its degradation products. There were no interference from sample and its degraded products the peak purity of both Valsartan and fenofibrate were 0.9991 and 0.9998. It shows that developed analytical method is specific for the analysis of both Valsartan and fenofibrate.

Precision: The precision of the method was established by carrying out the analysis of the analyte $(n=6)$ using the proposed method. The chromatogram for standard was given in Fig. 3. The value of standard deviation shows that the method is precise. The results obtained are presented in Table- 1 .

Recovery studies: To check the accuracy of the proposed method, recovery studies were carried out at 50, 100 and $150 \%$ of the test concentration as per $\mathrm{ICH}$ guidelines. The recovery study was performed three times at each level.

Robustness of method: The robustness of the developed method was studied by making small deliberate variations in the method parameters such as the small components in the mobile phase, flow rate, wavelength and the column temperature. The results of the robustness study are within the critical value.

Ruggedness: Ruggedness test was determined between two different analysts, instruments and columns. The value of

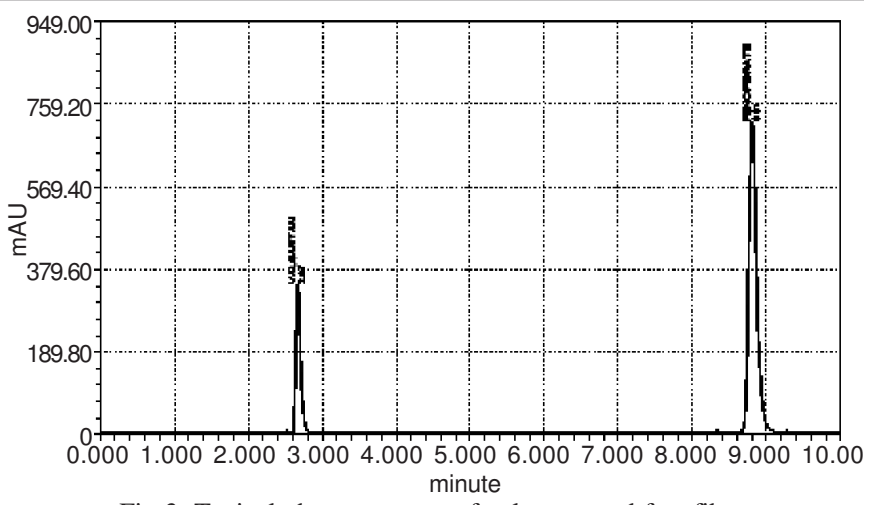

Fig 3. Typical chromatogram of valsartan and fenofibrate

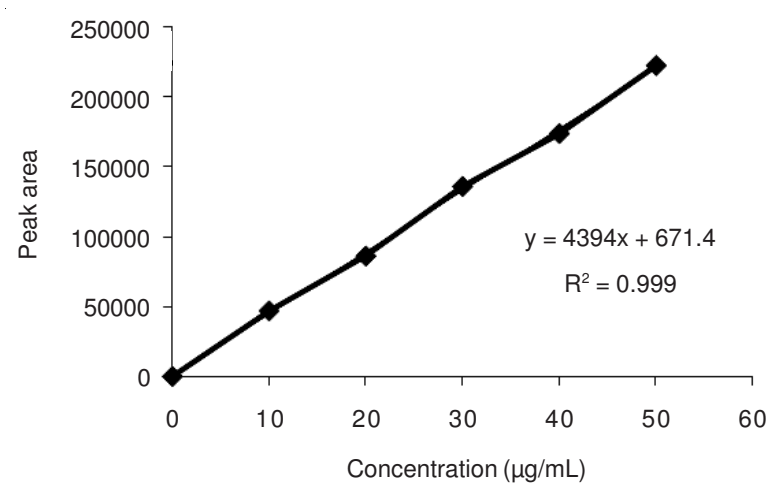

Fig 4: Linearity of valsartan

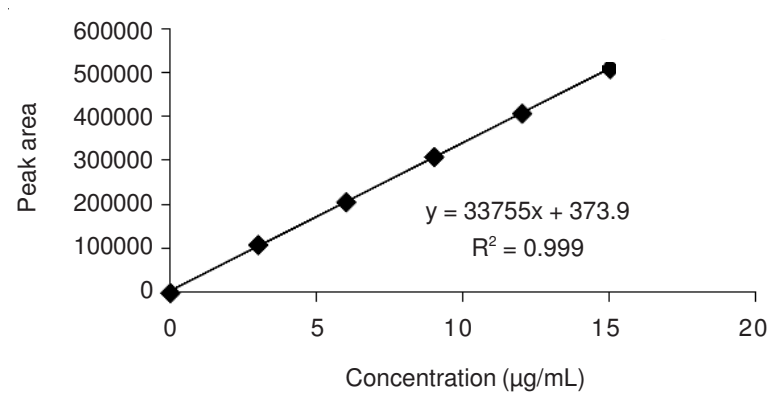

Fig. 5. Linearity of fenofibrate

percentage RSD was below $2.0 \%$, exhibits the ruggedness of developed analytical method.

Solution stability studies: The sample solution was prepared at test concentration and initial assay was determined. Solution was stored up to $24 \mathrm{~h}$ at room temperature and about $4{ }^{\circ} \mathrm{C}$ and assay was determined at $4,8,12$ and $24 \mathrm{~h}$ against freshly prepared standard and also analyzed about $4^{\circ} \mathrm{C}$ at $24 \mathrm{~h}$. The assay obtained at different time intervals was compared with the initial assay value and recorded. The relative standard deviation was found below $2 \%$. It proves that both standard and sample solutions are stable up to $24 \mathrm{~h}$ at room temperature and at $4{ }^{\circ} \mathrm{C}$ and results are given in Table-1.

\section{ACKNOWLEDGEMENTS}

The authors thankful to Microlabs Limited, Bangalore for providing gift sample of valsartan and fenofibrate. The authors thankful to the management of Nova College of Pharmaceutical Education and Research, Jupudi for providing necessary facilities to carry out this research work. 


\section{REFERENCES}

1. D.A. Tomalia and H.D. Durst, in ed.: E. Weber, Supramolecular Chemistry I-Directed Synthesis and Molecular Recognition. In Topics in Current Chemistry; Ed.; Springer-Verlag: Berlin, vol. 165, p. 193 (1993).

2. P.B. Smith, S.J. Martin, M.J. Hall and D.A. Tomalia, in ed.: J. Mitchell, Characterization of the Structure and Synthetic Reactions of Polyamidoamine "STARBURST" Polymers. In Applied Polymer Analysis Characterization; Hanser: Munich, pp. 357-385 (1987).

3. J.M.J. Frechet, S. Matuszczak, H.D.H. Stover, B. Reck and C.G. Willson, The Electrophilic Aromatic Substitution Approach. In Polymers in Microlithography; ACS Symposium Series 412; American Chemical Society: Washington, DC, pp. 74-86 (1989).

4. D.A. Tomalia, J.R. Dewald, M.R. Hall, S.J. Martin and P.P. Smith, Preprints of the 1st SPSJ International Polymer Conference, Society of Polymer Science Japan, Kyoto, p. 65 (1984).

5. H. Staudinger, In From Organic Chemistry to Macromolecules; Wiley Interscience: New York (1970).

6. D. Brabender-Van Den Berg and E.M. Meijer, Angew. Chem. Int. Ed. Engl., 32, 1665 (1993)

7. D. Bhadra, A.K. Yadav, S. Bhadra and N.K. Jain, Int. J. Pharm., 295, 221 (2005)

8. E. Francotte, A. Davatz and P. Richert, J. Chromatogr. B: Biomed. Appl., 686, 77 (1996).

9. Z.Z. Piao, E.S. Lee, H.T. Tran and B.J. Lee, Arch. Pharm. Res., 31, 1055 (2008)

10. G. Iriarte, N. Ferreiros, I. Ibarrondo, R.M. Alonso and M. Itxaso Maguregui, J. Sep. Sci., 30, 2231 (2007).

11. A. Sampath, A.R. Reddy, B. Yakambaram, A. Thirupathi, M. Prabhakar, P.P. Reddy and V.P. Reddy, J. Pharm. Biomed. Anal., 50, 405 (2009).

12. D. Zhang, X. Du, M. Liu, H. Li, Y. Jiang, L. Zhao and J. Gu, $J$ Chromatogr. B: Anal. Technol. Biomed. Life Sci., 863, 223 (2008).

13. J. Macek, J. Klima and P. Ptacek, J. Chromatogr. B: Anal. Technol. Biomed. Life Sci., 832, 169 (2006).

14. N. Ferreiros, G. Iriarte, R.M. Alonso, R.M. Jimenez and E. Ortiz, J. Sep. Sci., 31, 667 (2008)
15. A. Zarghi, A. Shafaati, S.M. Foroutan and H. Movahed, Sci. Pharm., 76, 439 (2008)

16. H.H. Maurer and T. Kraemer, Arlt. Ther. Drug Monit., 20, 706 (1998).

17. I.E. Panderi and P.M. Parissi, J. Pharm. Biomed. Anal., 21, 1017 (1999).

18. D. Farthing, I. Fakhry, E.B. Ripley and D. Sica, J. Pharm. Biomed. Anal., 17, 1455 (1998).

19. K. Richter, R. Oertel and W. Kirch, J. Chromatogr. A, 729, 293 (1996).

20. C.V. Prasad, C. Parihar, K. Sunil and P. Parimoo, J. Pharm. Biomed. Anal., 17, 877 (1998).

21. N.J. Shah, B.N. Suhagia, R.R. Shah and N.M. Patel, Indian J. Pharm. Sci., 71, 72 (2009).

22. B. Kocyigit-Kaymakcoglu, S. Unsalan and S. Rollas, Pharmazie, 61, 586 (2006).

23. S.C. Sweetman, Martindale-The Complete Drug Reference, Pharmaceutical Press, edn 33 (2002).

24. K. Reddersen and T. Heberer, J. Sep. Sci., 26, 1443 (2003).

25. F. Sacher, F.T. Lange, H.J. Brauch and I. Blankenhorn, J. Chromatogr. A, 938, 199 (2001).

26. British Pharmacopeia, Her Majesty Stationery Office, London (2001).

27. European Pharmacopoeia, Council of Europe, Strasbourg, France, edn. 4 (2002).

28. L.A. Romanyshyn and P.R. Tiller, J. Chromatogr. A, 928, 41 (2001).

29. G.R. Fan, M. Lin, Z.X. Zhang and D.K. An, Yaowu Fenxi Zazhi, 20, 231 (2000)

30. B. Streel, P. Hubert and A. Ceccato, J. Chromatogr. B Biomed. Appl., 742, 391 (2000).

31. S. Abe, K. Ono, M. Mogi and T. Hayashi, Yakugaku Zasshi, 118, 447 (1998).

32. L.D. Masnatta, L.A. Cuniberti, R.H. Rey and J.P. Werba, J. Chromatogr. B: Biomed. Appl., 687, 437 (1996).

33. A.C. Ramusino and A. Carozzi, J. Chromatogr. Biomed. Appl., 56, 419 (1986).

34. R.N. Rao and V. Nagaraju, J. Pharm. Biomed. Anal., 33, 335 (2003).

35. X. Ji and C.Ye, ZhongguoYaoke Daxue Xuebao, 18, 284 (1987).

36. P.M. Lacroix, B.A. Dawson, R.W. Sears, D.B. Black, T.D. Cyr and J.C. Ethier, J. Pharm. Biomed. Anal., 18, 383 (1998). 